No. 11(18)

\title{
A BASIC FORMALIZATION OF THE INTERACTION OF THE KEY STAKEHOLDERS OF AN INNOVATION ECOSYSTEM
}

\author{
Igor N. Dubina
}

\begin{abstract}
This paper presents an attempt to formalize the concept of the Triple Helix of university-government-industry interactions as a prototype of an innovation ecosystem. Such a formalization is based on game theory principles, methods and models, as well as the methods and instruments of the theory of optimal allocation of resources. The constructed game-theoretic model simulates the phases of $\mathrm{R} \& \mathrm{D}$, the implementation and commercialization of a new project, as well as the risks and uncertainty in each of these innovation stages.
\end{abstract}

Keywords: innovation ecosystem, game theory, optimal resources allocation, Triple Helix.

JEL Classification: C61; C70; C92.

DOI: $10.15611 /$ me.2015.11.03.

\section{Introduction}

Recently, "innovation" has become one of the most popular words, both in developed and emerging economies. However, in many cases, especially in economies-in-transition, it remains to be used just as a word, not an action. One of the reasons for this situation is the problem of weakly functioning innovation ecosystems which consist in such key stakeholders as government, universities and research centers, industries, investors, innovation consumers, and others.

So, the key question in this context is as follows: how can and should innovation ecosystem stakeholders effectively interact in order to produce new and right ideas and successfully commercialize them under the risks and uncertainty of a social and natural environment?

Looking for a way to analyze the interactions of innovation ecosystem stakeholders, we apply some formal methods. This paper presents an attempt to formalize the concept of the Triple Helix of university-

\footnotetext{
Igor N. Dubina

Novosibirsk National Research State University

Altai State University

igor_dubina@yahoo.com
} 
government-industry interactions as a prototype of an innovation ecosystem. Such a formalization is based on both conceptual elements of institutional economics, innovation economics and management, and formal gametheoretic principles, approaches, methods and mathematical models, as well as the methods and instruments of the theory of optimal allocation of resources.

The game theory, which officially started with the canonical book of J. von Neumann and O. Morgenstern (1944), can be defined as a logical and mathematical theory of strategic decision-making under competition, risk and uncertainty; a theory of optimal and effective rational behavior; or a theory of compromises and conflict resolution [Dubina 2013].

In particular, this paper introduces a new game-theoretic model that was designed with the aim to educate, simulate and analyze how the main innovation stakeholders (government, universities, and industries) can and should multilaterally interact through a non-linear and multistage communication in order to reach a systemic compromise [Algazin 2009] of their interests, objectives and behaviors in an innovational and entrepreneurial ecosystem and a social, political, economic and natural environment fraught with risk and uncertainty.

\section{The concept of the Triple Helix of innovation and an innovation ecosystem}

The basic conceptual and contextual framework for this work is the concept of the Triple Helix of university-industry-government relationships [Etzkowitz, Leydesdorff 1995]. This concept reflects the shift from a dominating industry-government dyad in Industrial Society to a growing triadic relationship between university-industry-government in Knowledge Society. Therefore, the Triple Helix accents a more prominent role for the university in the production, transfer and application of knowledge. In this way, a classical understanding of a university as a knowledge creator and transmitter is added with the concept of Entrepreneurial University that also actively promotes knowledge in a society and puts knowledge to use in the interaction with other innovation actors and stakeholders. Entrepreneurial universities also have an enhanced capacity to generate technology that has changed their position from a traditional source of human resources and knowledge to a new source of technology generation and transfer. In the Triple Helix conception, government also acts as a public entrepreneur and venture capitalist, in addition to its traditional regulatory role in setting the rules of the game [Ranga, Etzkowitz 2013]. 
We consider this game as a prototype of an innovation ecosystem which could be extended to more complex systems with more categories of participants, e.g. investors, consumers, etc. As an example, the concept of the Triple Helix has been further developed toward the Quadruple Helix [Carayannis, Campbell 2009] by adding “civil society” (citizens) as the fourth helix and the Quintuple Helix (Figure 1) that adds Environment as a challenge and driver for innovation [Carayannis, Barth, Campbell 2012]. Such development of the initial formulation of the Triple Helix concept led to to the N-tuple Innovation Helix concept [Park 2014].

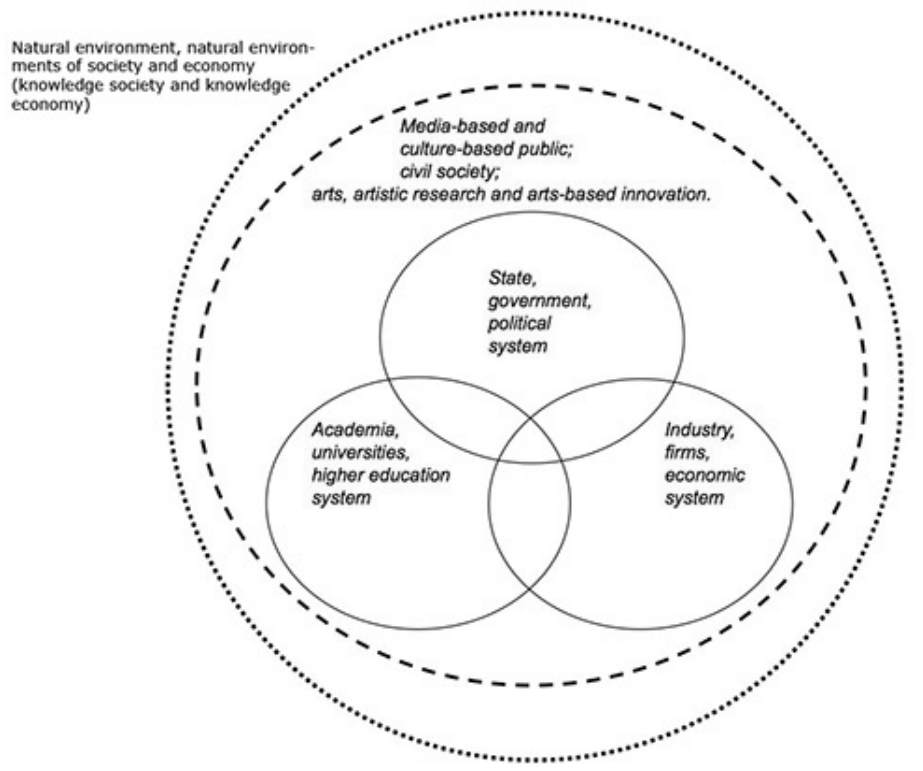

Fig. 1. The concept of the Quintuple Innovation Helix

Source: [Carayannis, Barth, Campbell 2012].

In different economies, the roles of different "innovation helix" actors also differ, as well as general strategies for innovative development. For example, in Russia, China, some Central Asian, Latin American and Eastern European countries, government plays a leading role, driving academia and industry [Ranga, Etzkowitz 2013]. Such an interaction configuration defines a dominated "top to bottom" innovation strategy. In the US and many Western European countries, there is a laissez-faire configuration, characterized by a limited state intervention in the economy and a limited control over universities which are more active in initiating social, political, economic and 
technological innovation, with industry as a driving force for innovation (a "bottom-top" innovation strategy). Such a difference in economic and innovation models requires making specifications of the game respectively to the kind of the economy.

In any case, the main stakeholders of an innovation ecosystem have to interact on different stages and phases, like a venture project development $(R \& D)$ phase, a new project implementation phase, and a new product commercialization phase. Each of these phases is connected with risks and uncertainty. So, a game model should represent and simulate the interaction on all of these phases under risk, uncertainty and unpredictability.

\section{A basic game-theoretic model}

This game is based on our previous studies of game-theoretic models for organizing innovative activities [Dubina 2013], and was designed pursuing several goals and objectives, depending on the game's "maturity". First of all, it is an educational goal, namely teaching and training possible strategies and ways of the interaction of the main innovation stakeholders (government, universities, and industries); game-theoretic principles of optimal strategic and tactical decision-making; the influence of uncertainty and risk in decision-making of the stakeholders.

The second goal relates to the next stage of the model development and it has an analytical character. This game can be used for the identification, systematization and analysis of stable patterns in the interactions and outcomes of the game's players.

The third main goal of designing this game relates to conditional forecasting and policy support by predicting a change direction of the players' behavior after certain interventions.

Generally, this game assumes that:

- there are several R\&D projects to be developed and implemented which are characterized with different costs and expected outcomes;

- all players have different resources to invest in R\&D and innovation;

- university initiates R\&D projects and allocate some resources for the selected project (Stage 1);

- government supports and invests in some initiated R\&D project (Stage 2);

- industry chooses projects for development, investment and implementation (Stage 3). 
Formally, this game is a 3-stage dynamic game with the inputs as follows:

- $n=3$ is the number of players;

- $R_{i}$ is the amount of resources available to player $i ; i=1, \ldots, n$;

- $m$ is the number of venture projects available in the game;

- $C D \min _{j}, C D m a x_{j}$ are the minimum and maximum cost of the development of project $j ; j=1, \ldots, m$;

- $\operatorname{CImin}_{j}, \operatorname{CImax}_{j}$ are the minimum and maximum cost of the implementation of project $j$;

- $E R_{j}$ is the expected output (revenue) from project $j$;

- $\alpha$ is the parameter of interest (yield) of investing in a standard (norisk) project.

From a game-theoretic point of view, there is also such a player as "Nature" that brings risks of the project development and implementation to the game, as well as uncertainty of players' payoffs and game outcomes. This game simulates risks and uncertainty at all the considered phases using random variables $(\mu, \phi, \xi)$.

This game is formalized as a multiple reciprocal principal-agent model as follows.

Players' actions:

- $X_{i j}$ is the fund provided by player $i$ for the development of project $j$; $i=1, \ldots, n ; j=1, \ldots, m ; \sum_{i} X_{i j} \leq R_{i}$.

- $Y_{i j}$ is the fund provided by player $i$ for the implementation of project $j$; $i=1, \ldots, n ; j=1, \ldots, m+1$, where $Y_{i m+1}$ is the fund invested in a standard (no-risk) project by player $i$.

Game outcomes:

- $F D_{j}=\sum_{i} X_{i j}(j=1, \ldots, m)$ is the fund collected for project $j$ at Stage 1;

- $p_{j}=\left(F D_{j}-C D \min _{j}\right) /\left(C D \max _{j}-C D \min _{j}\right)(j=1, \ldots, m)$ is the probability of the successful development of project $j, 0 \leq p_{j} \leq 1$;

- $\mu_{j}$ is a random variable with uniform distribution (e.g. it can be generated by MS Excel RAND() function), $0 \leq \mu_{j} \leq 1$. If $\mu_{j} \leq p_{j}$, project $j$ is successfully realized (developed) and can potentially bring some outcome to the investor. If $\mu_{j}>p_{j}$, the project is not developed and the investor gets nothing from it; tation;

- $F I_{j}=\sum_{i} Y_{i j}(j=1, \ldots, m)$ is the fund collected for project $j$ implemen-

- $q_{j}=\left(F I_{j}-\operatorname{CImin}_{j}\right) /\left(\operatorname{CImax}_{j}-\operatorname{CImin}_{j}\right)(j=1, \ldots, m)$ is the probability of successful development of project $j, 0 \leq q \leq 1$;

- $\phi j$ is a random variable generated by RAND(), $0 \leq \phi_{j} \leq 1$. If $\phi_{j} \leq q_{j}$, the project is successfully realized (implemented) and brings some revenue to 
the investor. If $\phi_{j}>p_{j}$, the project is not implemented and the investor gets nothing from it;

- $\xi_{j}$ is a random variable which characterizes the commercial success of the implemented project and it can be generated, e.g. by MS Excel RAND() or NORMDIST(...) functions;

- $R R_{j}, j=1, \ldots, m$, is the real outcome / revenue gained from project $j$ and it may differ from the expected outcome / revenue $\left(E R_{j}\right)$. If $\xi_{j}$ is generated by $\operatorname{RAND}(), 0 \leq \xi_{j} \leq 1$, the real outcome can be calculated, for example, as follows: $R R_{j}=E R_{j}\left(1.5-\xi_{j}\right)$.

So, in this case, the real outcome may differ from the expected outcome in $50 \%$ on both sides. This rule can be conventionally changed before the game starts. For example, if $R R_{j}=E R_{j}\left(1.25-\xi_{j} / 2\right)$, the real outcome may differ from the expected outcome in $25 \%$ on both sides.

- $N R_{i}=Y_{i m+1}(1+\alpha)(i=1, \ldots, n)$ is the revenue of player $i$ from investment in a standard (no-risk) project;

- $T R I=\sum_{j} R R_{j}(j=1, \ldots, m)$ is the total real revenue gained from the venture projects (VDP); (GDP).

- $\mathrm{TR}=\mathrm{TRI}+\sum_{i} N R_{i}(i=1, \ldots, n)$ is the total revenue in this game

Based on this formalization, all players' objective functions and payoffs in this basic game can be identified as follows:

- university: $U_{U n i}=\max \sum_{i j}\left(X_{i j}-X_{1 j}\right)$ (maximization of funds collected for developed projects by the choice of $X_{1 j}$ values controlled by universities);

- government: $U_{G o v}=\max \left\{\sum_{i j} p_{j}\left(X_{i j}\right) q_{j}\left(Y_{i j}\right) E R j+\sum_{i} N R_{i}\left(Y_{i m+1}\right)\right\}$ (maximization of total expected revenue by the choice of those $X_{2 j}$ and $Y_{2 j}$ values which are controlled by government);

- industry: $U_{\text {Ind }}=\max \left\{\sum_{j} p_{j}\left(X_{i j}\right) q_{j}\left(Y_{i j}\right) E R j+\sum_{i} N R_{3}\left(Y_{3 m+1}\right)-X_{3 j}-Y_{3 j}\right\}$ (maximization of industry's profit by the choice of those $X_{3 j}$ and $Y_{3 j}$ values which are controlled by industry).

These objective functions are to be specified for a game with a certain number and character of players. Such a game-theoretic model requires further development in terms of an algorithm and a software tool for solving this game (e.g. for defining a Nash equilibrium, Pareto optimal situations, and Kaldor-Hicks improvements). In this way, this model could serve as a possible benchmark for the real interactions of innovation stakeholders. 


\section{A business simulation game}

Based on the presented formalization as well as on the experience of designing business management games, or "innovation games" [Musshoff et al. 2011; Hohmann 2013], we developed and tested a series of business simulation games. Those games included three categories of players as indicated in the Triple Helix conception (Government-UniversitiesIndustries) and two additional actors (Investors and Civil Societies/Innovation Consumers).

Initially, these games were tested in several student groups in Altai State University (Russia). We have piloted a business management game (called "Lab to Industry") that simulated the interaction of several groups really representing such categories of innovation stakeholders like government, universities, industries, and investors in Moscow State Technological University and the Skolkovo School of Management (Moscow, May 18-20, 2015).

In particular, this game has clearly demonstrated the huge intercommunication and inter-understanding gap between the main innovation stakeholders (government, universities, industries and investors) because of their unwillingness and inability to search for a compromise. And that seems to be a systemic problem not just for Russia, but also for many other economies in transition.

Such a game really helps to better understand the motives, interests, possible strategies and ways of the interaction of the main innovation stakeholders and may serve as an instrument of developing mutual understanding and compromises. Recently we have started replicating this game in Russian universities, local government and businesses, "innovation fairs", "innovation saloons”, etc.

\section{Optimal resource allocation theory as a benchmark}

Another possible benchmark could be the case when all the stakeholders have agreed to act as a single decision-maker for allocating their resources in the most effective way. That case would be equivalent to the canonical approach of the transportation theory (optimal allocation of resources) developed by L. Kantorovich. In particular cases, such an optimization problem can be formalized as follows.

- Objective function: $\max \left\{\sum_{j} p_{j}\left(X_{i j}\right) q_{j}\left(Y_{i j}\right) E R j+\sum_{i} N R_{i}\left(Y_{i m+1}\right)\right\}$ (maximization of total expected revenue by a choice of $X_{i j}$ and $Y_{i j}$ values); 
- Constraints: $\sum_{\mathrm{j}}\left(X_{\mathrm{ij}}+Y_{i j}\right)+Y_{i m+1} \leq R_{i} ; p_{j} \leq 1 ; q_{j} \leq 1 ; i=1, \ldots, n, j=1, \ldots, m$.

This optimization problem can be solved, for example, with the tools available in MS Excel Solver. The benchmark for game outcomes can be defined this way.

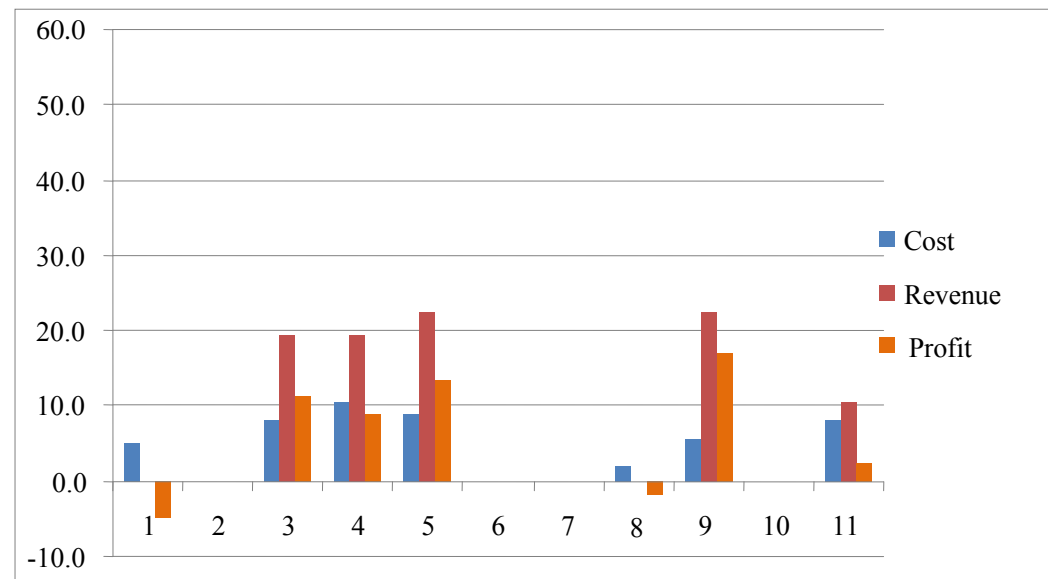

Fig. 2. Distribution of resources and outcomes among the projects in the simulation game

Source: author’s own elaboration.

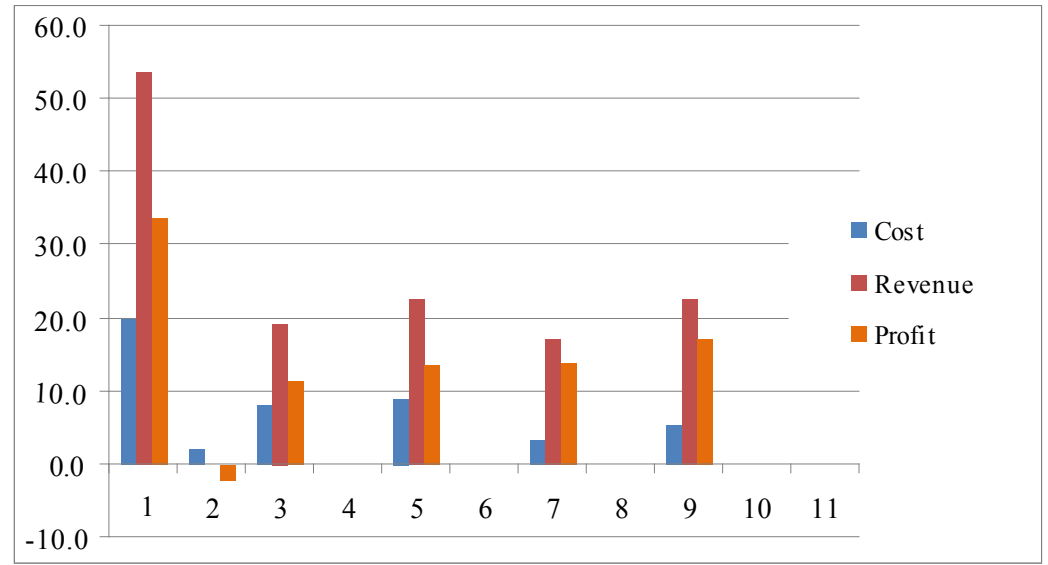

Fig. 3. Distribution of resources and outcomes among the projects according to the benchmark

Source: author's own elaboration. 
An example of the contrast of decision-making in a group interaction within the conducted simulation game and an application of this method for $10(j=1, \ldots, 10)$ venture projects and a non-risk project $(j=11)$ is presented in Figures 2 and 3. The total resources and investments in these cases were 48 units, while the total revenue and profit for the first case were 94 and 46 units respectively, and the same values for the second case were 136 and 88 units respectively.

\section{Conclusion}

Due to the rather sophisticated character of the real innovation ecosystem, the interaction of its active elements (e.g. government, universities, industries, and investors) is very complicated. Hence, in this complex, dynamic and non-linear landscape of public-private collaboration and competition, game-theoretic perspectives and other formal approaches can be powerful tools for theory, policy, and practice, allowing to deal with some related challenges and opportunities. The suggested basic model of a multilevel hierarchical game can be an initial platform for further developing a theoretical framework based on the Triple Helix concept.

The designed simulation game may serve as an empirical platform for analysis and support of decision-making for innovation policymakers and practitioners. At the same time, a formal mathematical model of the interaction of the key innovation stakeholders may contribute to a general theoretical framework for Innovation Economics and Management. In particular, the game-theoretic solutions regarding the optimal strategies of the key stakeholders of an innovation ecosystem may serve as the benchmark for their real interactions.

\section{Acknowledgments}

The author thanks Prof. Dr. Elias Carayannis (George Washington University, Washington, DC, USA) for discussing the general idea of creating an innovation game in the context of the Triple Innovation Helix concept, and Prof. Dr. Norbert Hirschauer (Martin Luther University HalleWittenberg, Halle, Germany) for his kind advisory role regarding the theoretical and methodological aspects of designing and organizing business management games, as well as the anonymous reviewers of the Journal of Mathematical Economics for their evaluation and recommendations. 


\section{References}

Algazin G.I. (2009). Models of Systemic Compromise in Socio-Economic Research. Barnaul. Azbuka (in Russian).

Carayannis E., Campbell D. (2009). "Mode 3" and "Quadruple Helix": toward a 21st century fractal innovation ecosystem. International Journal of Technology Management 46(3-4). Pp. 201-234.

Carayannis E.G., Barth T.D., Campbell D.F.J. (2012). The Quintuple Helix innovation model: global warming as a challenge and driver for innovation. Journal of Innovation and Entrepreneurship 1(2). Pp. 1-12.

Dubina I.N. (2013). Game-Theoretic Models for Organizing Creativity and Innovation in Firms. Barnaul Altai University (in Russian).

Etzkowitz H., Leydesdorff L. (1995). The Triple Helix: University - Industry Government relations a laboratory for knowledge based economic development. EASST Review 14 (1). Pp. 14-19.

Hohmann L. (2013). Innovation games: Creating Breakthrough Products Through Collaborative Play. MA. Addison-Wesley. Boston.

Musshoff O., Hirschauer N., Hengel P. (2011). Are business management games a suitable tool for analyzing the boundedly rational behavior of economic agents? Modern Economy 2. Pp. 468-478.

Park H.W. (2014). Transition from the Triple Helix to N-Tuple Helices? An interview with Elias G. Carayannis and David F. J. Campbell. Scientometrics 99. Pp. 203-207.

Ranga M., Etzkowitz H. (2013). Triple Helix systems: analytical framework for innovation policy and practice in the knowledge society. Industry and Higher Education 27(4). Pp. 237-262. 